\title{
Performans Değerlemesinde DEMATEL ve Bulanık TOPSIS Uygulaması
}

\author{
Performance Assessment in Turkish Sugar Plants By Using DEMATEL And Fuzzy TOPSIS \\ Methods
}

Meltem KARAATLI ${ }^{1}$, Nuri ÖMÜRBEK², Emrah IŞIK ${ }^{3}$, Ekrem YILMAZ ${ }^{4}$

\begin{abstract}
ÖZET
Bu çalışmada Türkiye Şeker Fabrikaları Anonim Şirketi adı altında toplanmış 23 şeker fabrikasının 2008-2012 yılları arasındaki verileri kullanılarak performans değerlendirmesi yapılmıştır. Çalışmada fiilen işlenen pancar, yakıt tüketimi, iş gücü, şeker üretimi, makine kapasitesi, melas miktarı ve satış miktarı kriter olarak dikkate alınmış ve bu kriterlerin ağırlıkları DEMATEL yöntemi ile hesaplanmıştır. Bu ağırlıklar kullanılarak bulanık TOPSIS yöntemi ile performans değerlemesi yapılmıştır. Bulanık TOPSIS uygulaması yapılırken tamamen gerçek verilerden yararlanılmıştır. Gerçek veriler üçgen bulanık sayılar kullanılarak bulanıklaştırılmıştır. Çalışmanın sonuçları incelendiğinde performans açısından Ereğli, Ilgın ve Eskişehir şeker fabrikaları ilk üçe girerken, Alpullu, Elazığ ve Kars şeker fabrikalarının son sıralarda yer aldığı görülmektedir.
\end{abstract}

Anahtar Kelimeler: Şeker Fabrikaları; Performans Analizi; Çok Kriterli Karar Verme; Bulanık TOPSIS; DEMATEL

\section{GíRiş}

Şeker pancarı Türkiye'de geniş bir alanda üretilmekle birlikte oldukça fazla pancar üreticisinin bulunduğu görülmektedir. Bu durumda pancarın sosyo-ekonomik yönünün önemini göstermektedir. Hem gıda güvencesinin sağlanması açısında hem de siyasi açıdan pancarönemli bir tarımsal ürün olmuştur. Bu nedenle son yıllarda uygulanan yüksek destekleme fiyatları ile yurt içinde oluşan talep fazlası üretim, stokları arttırmış ve şekerin ihracata yönlendirilmesini gerektirmiştir. Ancak, dünyada şeker fiyatlarının düşük seviyelerde seyretmesi destekleme ve ihracat maliyetlerini arttırmıştır. Böylece, şekeri desteklemek üzere Türkiye Şeker Fabrikaları Anonim Şirketi'ne ayrılan hazine kaynakları artmış ve tüketici daha pahalıya şeker tüketmek durumuyla karşılaşmıştır

\begin{abstract}
In this study, performances of 23 sugar plants of Turkish Sugar Plants CO. have been examined for the period 2008-2012. Criteria weights of practically processed beet, fuel consumption, labor, sugar production, machinery capacity, the amount of molasses, and the amount of sales have been calculated by using DEMATEL method. Using the weights, Fuzzy TOPSIS method utilized to analyze the performances of the plants. The actual data were converted to triangular fuzzy numbers for fuzzification to use in Fuzzy TOPSIS method. The results of the study show that the plants having the highest performance scores are Ereğli, Ilgın and Eskişehir, whereas the plants having the lowest performance scores are Alpullu, Elazığ and Kars, respectively.
\end{abstract}

Keywords Sugar Plants; Performance Analysis; Multi-Criteria Decision Making; Fuzzy TOPSIS; DEMATEL

(Kıymaz, 2001: 8-10).

Türkiye Şeker Fabrikaları A.Ş. 6 Temmuz 1935 tarihinde T.C Ziraat Bankası, Sümer Bank ve T.Işs Bankası'nın eşit oranda iştiraki ile ve o tarihte mevcut 4 adet şeker şirketini devralmak suretiyle Türk Ticaret Kanunu hükümlerine göre 22 milyon lira sermayeli bir anonim şirket olarak kurulmuştur (Türkiye Şeker Fabrikaları Anonim Şirketi 2012 Faaliyet Raporu, 2012:1). Günümüzde Türkiye Şeker Fabrikaları A.Ş Türkiye'nin çeşitli illerine dağılmış 23 fabrikası ile faaliyetlerini sürdürmektedir.

Şeker fabrikaları ile ilgili yapılan çalışmalar ve bu çalışmada performans değerlemede kullanılan bulanık TOPSIS yöntemlerinin kullanım alanları hakkında yapılan literatür taraması Tablo 1.'de görülmektedir. 
Tablo 1: Bulanık TOPSIS Yöntemi Kullanım Alanları

\begin{tabular}{|c|c|}
\hline BULANIK TOPSIS KULLANIM ALANLARI & ÇALIŞMA ÖRNEKLERI \\
\hline Makine Teçhizat Seçimi & -(Kaya, Kılınç ve Çevikcan, 2007: 8-14) \\
\hline Silah seçimi & -(Dağdeviren, Yavuz ve Kılıç, 2009: 8143-8151) \\
\hline Performans Değerlemesi & $\begin{array}{l}\text {-(Başkaya ve Ozturk, 2011: 77-100) } \\
\text {-(Perçin ve Karakaya, 2012: 241-266) } \\
\text {-(Zeydan, Çolpan and Çobanoğlu, 2011: 2741-2751) }\end{array}$ \\
\hline Kuruluş Yeri Seçimi & -(Çınar, 2010: 37-45) \\
\hline $\begin{array}{l}\text { Gurup Kararı } \\
\text { Karar verme }\end{array}$ & $\begin{array}{l}-(\text { Chen, 2000: 1-9) } \\
-(\text { Ecer, 2006: 77-96) }\end{array}$ \\
\hline Madencilik & -(Eleren ve Ersoy, 2007: 9-22) \\
\hline Tedarikçi Seçimi & $\begin{array}{l}\text {-(Boran, Genç, Kurt ve Akay, 2009: 11363-11368) } \\
\text {-(Chen, Lin and Huang, 2006: 289-301) } \\
\text {-(Demir, 2010:) } \\
\text {-(Wang, Cheng and Huang, 2009: 377-386) }\end{array}$ \\
\hline Savunma Sanayi & $-($ Kabak, 2011: 1-17) \\
\hline Lojistik Destek & -(Kannan, Pokharel and Kumar, 2009: 28-36) \\
\hline Şehir Planlaması & -(Awasthi and Chauhan 2012: 573-584) \\
\hline Mühendislik ve Bilgisayar & -(Madi and Osman, 2011:) \\
\hline Turizm sektörü & $\begin{array}{l}\text {-(Benitez, Martin and Roman, 2007: 544-555) } \\
\text {-(Huang and Peng, 2012: 456-465) }\end{array}$ \\
\hline Proje Seçimi & -(Amiri, 2010: 6218-6224) \\
\hline $\begin{array}{c}\text { ŞEKER FABRIKALARI HAKKINDA } \\
\text { ÇALIŞMALAR }\end{array}$ & $\begin{array}{c}\text { ŞERKER FABRIKALARI HAKKINDA ÇALIŞMA } \\
\text { ÖRNEKLERI }\end{array}$ \\
\hline Etkinlik Analizi & $\begin{array}{l}\text {-(Çakır ve Perçin, 2012: 49-63) } \\
\text {-(Taşdoğan ve Taşdoğan, 2012: 59-77) }\end{array}$ \\
\hline Performans Ölçümü & -(Aslan, 2007: 383-396) \\
\hline
\end{tabular}


Şeker fabrikalarında performans değerleme ve etkinlik analizi üzerine yapılan bazı çalışmalardan; Taşdoğan ve Taşdoğan (2012: 59-77) Türkiye Şeker Fabrikaları Anonim Şirketine (TŞFAŞ) bağlı 23 fabrikanın 1994-2009 dönemine ait ara malı ve nihai mal üretim etkinliğini panel veri setine dayanan malmquist endeksini kullanarak incelemişlerdir. Çakır ve Perçin (2012: 49-63) ise TŞFAŞ'ne ait 23 ait kamu şeker fabrikasında 2009 yılı için veri zarflama analizi ile göreli etkinlik ölçümü yapmışlardır. Aslan (2007: 383-397) Türkiye'deki şeker fabrikalarının etkinlik düzeylerinin tespit edilmesi ve şeker fabrikalarının tam etkin konuma gelebilmeleri için azaltmaları veya arttırmaları gereken kaynakların belirlenmesi amacıyla bir çalışma yapmıştır. Çalışma kapsamına 23 şeker fabrikası alınmıştır. Şeker fabrikalarının etkinlik düzeylerini ölçmek için veri zarflama analizi tekniğinden faydalanmıştır.

Bu çalışmada da 2008-2012 yılları dikkate alınarak Türkiye Şeker Fabrikaları Anonim Şirketi bünyesinde bulunan 23 şeker fabrikasının performansları değerlendirilmiştir. Şeker fabrikalarının performanslarının değerlendirilmesinde uzman görüşleri DEMATEL yönteminde kullanılarak kriter ağırlıkları belirlenmiştir. Performans değerlendirme aşamasında ise tamamen gerçek veriler kullanılarak beş yıllık veri üçgen bulanık sayılar kullanılarak bulanıklaştırılmış ve bulanık TOPSIS yöntemi uygulanmıştır.

\section{2. ÇOK KRITERLI KARAR VERME YÖNTEMLERI}

Çok Kriterli Karar Verme Yöntemleri (ÇKKVY), karar verme sürecine yardımcı olmak amacıyla birbiriyle çelişen kriterleri dikkate alarak, bir dizi alternatif arasından seçim yapmak ya da alternatifleri sıralamak amacıyla geliştirilmiştir (Mulliner, Smallbone ve Maliene 2013: 271). Çok kriterli karar verme sürecinde tercih yapılarının belirlenmesinde karar vericinin tercihine dayalı olarak alternatiflerin karşılaştırılması çok önemlidir. Kriterin önemi karar vermenin kalitesini artıracaktır (Yang ve Tzeng, 2011: 1417). Literatürde birçok çok kriterli karar verme tekniği bulunmaktadır. Bir tekniğin diğerine göre tercih edilmesinde hangi yöntemin kullanılacağına dair kesin bir sebep bulunmamaktadır. Herhangi bir, çok kriterli karar verme yöntemini seçmek için en önemli kriter problemin amacı ile uyumluluğudur. Amaç alternatiflerin sıralanması ise sıralama yapan tekniklerden biri tercih edilebilir. Kullanılan yöntemin nitelikselin ve nicelikselin doğasında yer alan pozitif ve negatif etkilerin her ikisini de işleyebilecek yeteneğe sahip olmakla birlikte kolay ve anlaşılır olması da önemlidir (Mulliner ve ark., 2013: 274).

\subsection{DEMATEL Yöntemi}

DEMATEL (The Decision Making Trial And Evaulation Laboratory) yöntemi araştırmada karmaşık ve birbirine girmiş problem gruplarının çözümünde kullanılması amacıyla 1972-1976 yılları arasında Cenevre Batelle Memorial Enstitüsü, bilim ve insan ilişkileri programı tarafından geliştirilmiştir (Fontela ve Gabus, 1974: 67-69). DEMATEL, faktörler seti arasında diyagramlar ve matrisler yardımıla nedensel ilişkileri ortaya koyan yapısal bir model analizidir. Yöntem; bileşenler arasındaki ilişkileri diyagramlar ve matrislerle tanımlayarak, bu ilişkiler arasında kantitatif tanımlamalar yaparak ilişkiler arasındaki gücü ortaya koymaktadır (Bai ve Sarkis, 2013: 285).

DEMATEL yöntemi 5 adımdan oluşmaktadır (Aksakal ve Dağdeviren, 2010: 907-908; SeyedHosseini, Safaei ve Asgharpour, 2006: 874-875; Tsai ve Chou, 2009: 1444-1455; Wu ve Lee, 2007: 501-502).

Adım 1: Direk ilişki matrisinin oluşturulması. Tablo 2.'de görüldüğü gibi beş seviyeden oluşan ikili karşılaştırma ölçeği kullanılarak direkt ilişki matrisi oluşturulur.

Tablo 2: DEMATEL Değerlendirme Ölçeği

\begin{tabular}{|c|c|}
\hline Sayısal Değer & Tanım \\
\hline 0 & Etkisiz \\
\hline 1 & Düşük etki \\
\hline 2 & Orta etki \\
\hline 3 & Yüksek etki \\
\hline 4 & Çok yüksek etki \\
\hline
\end{tabular}

Kriterler arasındaki ilişkiler, ikili karşılaştırma ölçeği kullanılarak uzman grup tarafından belirlenir. Karşılaştırmaların sonucunda direk ilişki matrisi elde edilir.

Adım 2: Normalleştirilmiş direkt ilişki matrisinin belirlenmesi.

$$
\begin{aligned}
& \mathrm{M}=\mathrm{K}^{*} \mathrm{~A} \\
& k=\min \left\lfloor\frac{1}{\max _{\substack{j=1 \\
1 \leq i \leq n}}^{n}\left|a_{i j}\right|}, \frac{1}{\max \sum_{\substack{j=1 \\
1 \leq i \leq n}}^{n}\left|a_{i j}\right|}\right\rfloor \\
& i, j \in\{1,2,3, \ldots n\}
\end{aligned}
$$


Direk ilişki matrisi (A)'ya bağlı olarak 1 ve 2 numaralı eşitlikler kullanılarak normalleştirilmiş direkt ilişki matrisi (M) oluşturulur. Satır ve sütundaki en küçük değer (k) kullanılarak normalleştirilmiş direk ilişki matrisi (M) elde edilir. Bu matrisin ana köşegen değerleri 0 'dır.

Adım 3:Toplam ilişki matrisinin elde edilmesi.

Normalleştirilmiş direk ilişki matrisi elde edildikten sonra toplam ilişki matrisi (S) 3 numaralı eşitlik yardımıyla elde edilir. Bu eşitlikte birim matris (I) ile gösterilmektedir.

$$
\begin{aligned}
& S=M+M^{2}+M^{3}+\cdots=\sum_{i=1}^{\infty} M^{i} \\
& =M(I-M)^{-1}
\end{aligned}
$$

\section{Adım 4:Gönderici ve alıcı grubu hesaplanması.}

Gönderici ve alıcı gruplar eşitlik 4, 5 ve 6 numaralı eşitlik yardımıyla hesaplanır. S matrisindeki sütunlar toplamı (R), S matrisindeki satırlar toplamı (D)'yi göstermektedir. D ve $\mathrm{R}$ eşitliklerinin hesaplanmaları ile $D-R$ ve $D+R$ değerlerini kullanarak her bir kriterin diğerleri üzerindeki etkisi ve diğerleri ile ilişki düzeyi belirlenir. D-R'de pozitif değerlerlere sahip kriterlerin, diğer kriterler üzerinde daha yüksek etkiye sahip olduğunu göstermektedir. Bu tip kriterler gönderici olarak adlandırılmaktadır. D-R değeri için negatif değere sahip olan kriterler ise diğer kriterlerden daha fazla etkilenirler. Bu kriterlere ise alıcı adı verilmektedir. Öte yandan $D+R$ değerleri herhangi bir kriterin diğer kriterler ile arasındaki ilişkisini göstermektedir.

$$
\begin{aligned}
& S=\left[S_{i, j}\right]_{m^{*} n}, i, j \in\{1,2,3, \cdots, n\} \\
& D=\sum_{j=1}^{n} S_{i, j} \\
& R=\sum_{j=1}^{n} S_{i, j}
\end{aligned}
$$

$D+R$ ve $D-R$ 'den yaralanarak etki-yönlü graf diyagramı elde edilebilir. Karar vericiler tarafından belirlenen bir eşik değeri yardımıyla $\mathrm{S}$ matrisinde eşik değerden daha büyük etki değerine sahip bazı elemanlar seçilir ve etki yönlü graf diyagramı elde edilir. Yatay eksen $D+R$, düşey eksen $D-R^{\prime} y i$ gösteren bir koordinat düzleminde noktalar gösterilir.

Adım 5: Ağırlıkların hesaplanması. (Baykasoğlu, Kaplanoğlu, Durmuşoğlu ve Şahin, 2013: 902; Dalalah, Hayajneh ve Batieha, 2011: 8386)

$$
\begin{aligned}
& w_{i}=\left\{\left(D_{i}+R_{i}\right)^{2}+\left(D_{i}-R_{i}\right)^{2}\right\}^{1 / 2} \\
& w_{i}=\frac{w_{1}}{\sum_{i=1}^{n} w_{i}}
\end{aligned}
$$

Son olarak bulunan $D+R$ ve $D-R$ değerleri yardımı ile 7 ve 8 numaralı eşitlik kullanılarak ağırlıklar hesaplanır.

\subsection{Bulanık TOPSIS Yöntemi}

Bulanık kümelerde üyelik fonksiyonu çeşidi kadar bulanık sayı çeşidi bulunmaktadır. Ele alınan konuya göre değişik bulanık sayılar kullanılabilmektedir. Genel olarak pratik uygulamalarda üçgen (triangular) ve yamuk (trapezoidal) bulanık sayı kullanılmaktadır (Baykal ve Beyan, 2004: 234). Bu çalışmada işlem kolaylığı açısından üçgen bulanık sayı tercih edilmiştir.

Bir üçgen bulanık sayı " $\tilde{A}^{\prime \prime}\left(\mathrm{a}_{1}, \mathrm{a}_{2} \mathrm{a}_{3}\right)$ şeklinde gösterilir. $\mu_{\bar{A}}(\mathrm{x})$ üyelik fonksiyonu ise aşağıdaki gibi ifade edilir ve Şekil 1.'deki gibi gösterilir (Wang, 2014: 30).

$\mu_{\tilde{A}}(x)=\left\{\begin{array}{lr}1 & x=a_{2} \\ \frac{x-a_{1}}{a_{2}-a_{1}}, & a_{1} \leq x \leq a_{2} \\ \frac{a_{3}-x}{a_{3}-a_{2}}, & a_{2}<x \leq a_{3} \\ 0, & \text { diğer durumda }\end{array}\right\}$

Şekil 1: Üçgen Bulanık Sayı A'nın Üyelik Fonksiyonu

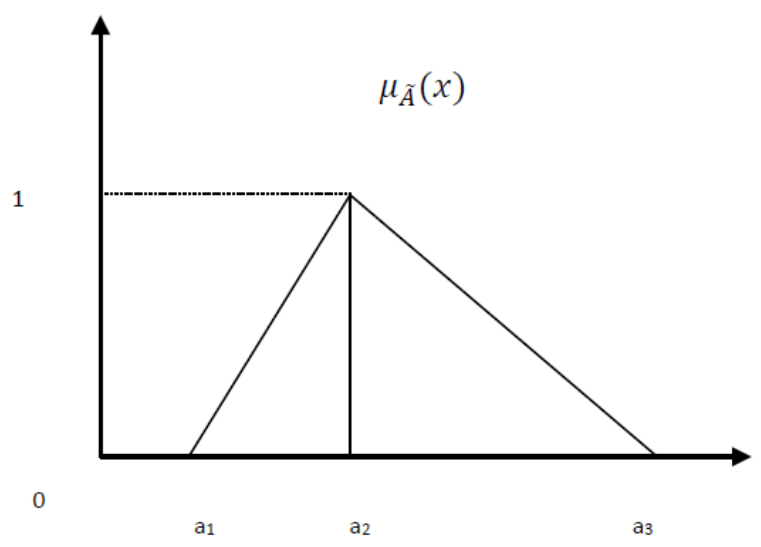

En çok bilinen ÇKKVY'lerden biri olan TOPSIS yöntemi 1981 yılında Hwang ve Yoon tarafından geliştirilmiştir. TOPSIS yönteminin temel amacl, seçilen alternatiflerin pozitif ideal çözüme en yakın, negatif ideal çözüme ise en uzak olan alternatiflerin belirlenmesidir. Literatür taramasında Wang, (2008: 1837-1845); Wang, Cheng ve Huang, (2009: 377386) ve Wang, (2014: 28-35) çalışmalarında kriter ağırlıklarını bulanık olarak düşünerek, gerçek 
finansal oranların kullanıldığı diğer bulanık TOPSIS çalışmalarından farklı olarak birden fazla periyodu birlikte değerlendiren bulanık TOPSIS çalışması yapmışlardır. Bu çalışmada da 2008-2012 yılları dikkate alınarak Türkiye Şeker Fabrikaları Anonim Şirketi bünyesinde bulunan 23 şeker fabrikasının performansları değerlendirilmiştir. Kriter ağıllıkları DEMATEL yöntemi ile hesaplanarak 2008-2012 yılları olmak üzere 5 periyot değerlendirilmiştir.

Wang, (2008: 1837-1845); Wang ve ark., (2009: 377-386) ve Wang, (2014: 28-35) çalışmalarında uyguladıkları bulanık TOPSIS modeli 8 adımdan oluşmaktadır:

Adım 1: Karar verici grubu ve değerlendirme kriterleri belirlenmesi.

Adım 2: Normalizasyon işleminin yapılması. Bu işlem için doğrusal normalizasyon uygulanmıştır (Shih, Shyur ve Lee, 2007: 805-806).

$r_{i j}=\frac{x_{i j}}{x^{*}} i=1,2, \ldots, m ; j=1,2, \ldots, n ; x_{j}^{*}=\max _{i}\left(x_{i j}\right)$ ölçüt için en iyi durum maksimizasyon ise

$r_{i i}=\frac{x_{j}^{-}}{-} i=1,2, \ldots, m ; j=1,2 \quad$ ölçüt için en iyi durum minimizasyon ise

Adım 3: $i=1,2 \ldots, m ; j=1,2, \ldots, n ; e=1,2, \ldots t \quad$ kriter için i. alternatifin gerçekleşen performansını ve e periyodunda i. alternatif j. kriter için normalize edilmiş değerini $b_{i j}(e)$ olarak göstermektedir. Normalleştirilmiş gerçek veriler kullanılarak bulanık karar matrisi 12 numaralı eşitlik yardımıyla bulanıklaştırılır (Wang, 2014: 29; Wang, 2008: 18371845; Wang ve Lee, 2010: 38-52).

$G_{i j}=\left(g_{1 j}, g_{2 j} g_{3 j}\right)$

$g_{1 j}=\min _{1 \leq e \leq t}\left\{b_{i j}(e)\right\}, g_{2 j}=\frac{1}{t} \sum_{e=1}^{t} b_{i j}(e), g_{3 j}=\max _{1 \leq e \leq t}\left\{b_{i j}(e)\right\}$.

$i=1,2, \ldots, m$ bütün kriterlerde $A_{i}$ alternatif matrisinin performansı $\left[G_{i 1}, G_{21}, \ldots G_{i n}\right]$ göstersin.

Adım 4: Pozitif $(A+)$ ve negatif $\left(A^{-}\right)$ideal çözümler 13 ve 14 numaralı eşitlikle hesaplanması.

$$
\begin{aligned}
& A^{+}=\left[G_{1}^{+}, G_{2}^{+}, \ldots, G_{3}^{+}\right] \\
& A^{-}=\left[G_{1}^{-}, G_{2}^{-}, \ldots, G_{3}^{-}\right]
\end{aligned}
$$

Burada;

$$
\begin{gathered}
G_{j}^{-}=\min _{1 \leq i \leq m}\left\{G_{i j}\right\}=\left(g_{1 j}^{-}, g_{2 j}^{-}, g_{3 j}^{-}\right) \text {ve } G_{j}^{+}=\max _{1 \leq i \leq m}\left\{G_{i j}\right\}=\left(g_{1 j}^{+}, g_{2 j}^{+}, g_{3 j}^{+}\right) \\
i=1,2, \ldots, m ; j=1,2, \ldots, n
\end{gathered}
$$

Adım 5: $G_{i j}$ 'den 'ye uzaklık değeri

$\left(d_{i} j^{-}\right) v e G_{i} j^{\prime} \operatorname{den} G_{j}^{+^{\prime}}$ ye $\left(d_{i} j^{+}\right)$uzaklık değerinin belirlenmesi. Eşitlik 15 ve eşitlik 16'da görülen formüller iki bulanık sayı arasındaki uzaklığı hesaplar.

$d_{i j}^{-}=d\left(G_{i j}, G_{j}^{-}\right)=\sqrt{\frac{1}{3}\left[\left(g_{1 i j}-g_{1 j}^{-}\right)^{2}+\left(g_{2 i j}-g_{2 j}^{-}\right)^{2}+\left(g_{3 i j}-g_{3 j}^{-}\right)^{2}\right]}$

$d_{i j}^{+}=d\left(G_{i j}, G_{j}^{+}\right)=\sqrt{\frac{1}{3}\left[\left(g_{1 i j}-g_{1 j}^{+}\right)^{2}+\left(g_{2 i j}-g_{2 j}^{+}\right)^{2}+\left(g_{3 i j}-g_{3 j}^{+}\right)^{2}\right]}$

$$
i=1,2, \ldots, m ; j=1,2, \ldots, n \text {. }
$$

Adım 6: $A_{i}$ alternatifinden pozitif ideal çözüme $\left(A^{+}\right)$ve negatif ideal çözüme $\left(A^{-}\right)$olan uzaklıkların ağırlıklandırılması. Ağırlıklandırılmış uzaklık değerleri $D_{i}^{-}$ve $D_{i}^{+}$ile gösterilir. 17 ve 18 numaralı eşitlikte görülmektedir.

$$
D_{i}^{-}=w_{1}^{*} d_{i 1}^{-}+w_{2} * d_{i 2}^{-}+\ldots+w_{n} * d_{i n}^{-}
$$

$D_{i}^{+}=w_{1} * d_{i 1}^{+}+w_{2} * d_{i 2}^{+}+\ldots+w_{n} * d_{i n}^{+}$

Adım 7: Her bir alternatifin pozitif ideal $A_{i}^{+}$ ve negatif ideal $A_{i}^{-}$çözümlerinin 19 numaralı eşitlik yardımıyla hesaplanması.

$$
\begin{array}{r}
A_{i}^{*}=\frac{A_{i}^{-}}{A_{i}^{-}+A_{i}^{+}} \quad l=1,2, \ldots, m .
\end{array}
$$

Adım 8: Yakınlık katsayılarının azalan şekilde sıralanması ile hangi alternatifin iyi olduğu ve hangisinin kötü olduğunun belirlenmesi.

\section{DEMATEL VE BULANIK TOPSIS YÖNTEMLERI ILE TÜRKIYE ŞEKER FABRIKALARININ PERFORMANS DEĞERLEMESI}

Çalışmanın bu bölümünde Türkiye Şeker Fabrikaları AŞ bünyesinde bulunan 23 şeker fabrikasının performansı değerlendirilmiştir. 
$\mathrm{Bu}$ değerleme yapılırken fiilen işlenen pancar (FiP), yakıt tüketimi (YT), işgücü (IG), şeker üretimi (ŞÜ), makine kapasitesi (MK), melas miktarı (MM) ve satış miktarı $(\mathrm{SM})$ kriterleri dikkate alınmıştır. Kriter ağırlıkları için uzman görüşüne başvurulmuş ve DEMATEL yöntemi ile ağırlıklar belirlenmiştir. Performans değerlendirme aşamasında ise tamamen gerçek veriler kullanılarak Bulanık TOPSIS yöntemi uygulanmıştır. Gerçek veriler üçgen bulanık sayılar kullanılarak bulanıklaştırılmıştır. Uzman görüşleri doğrultusunda dikkate alınan kriterler ve kodları
Tablo 3.' de verilmiştir.

\subsection{DEMATEL Yöntemi İle Kriter Ağırlıklarının} Hesaplanması

Adım 1: Direkt ilişki Matrisinin Hesaplanması

Çalışmada Tablo 2.'de DEMATEL değerlendirme ölçeği kullanılarak ikili karşılaştırma ölçeği yardımıyla Türkiye Şeker Fabrikalarında çalışan ve on kişiden oluşan konunun uzmanı bir ekibin görüşü alınmıştır. Daha sonra alınan uzman görüşlerinin ortalaması alınarak aşağıdaki direkt ilişki matrisi elde edilmiştir.

Tablo 3: Kriterler ve Kodları

\begin{tabular}{|c|c|}
\hline Kod & Kriter \\
\hline FiP & Fiilen İşlenen Pancar \\
YT & Yakıt Tüketimi \\
IG & Iş̧ Gücü \\
ŞÜ & Şeker Üretimi \\
MK & Makine Kapasitesi \\
MM & Melas Miktarı \\
SM & Satış Miktarı \\
\hline
\end{tabular}

Tablo 4: Direkt Illişki Matrisi

\begin{tabular}{|l|c|c|c|c|c|c|c|c|c|}
\hline & FiP & YT & iG & şÜ & MK & MM & SM & Toplam & Bölüm \\
\hline FiP & 0 & 3,8 & 3,6 & 4 & 1,2 & 4 & 2,5 & 19,1 & 0,052356021 \\
\hline YT & 1,5 & 0 & 0,4 & 3,5 & 2,6 & 0,8 & 1,2 & 10 & 0,1 \\
\hline í & 2,2 & 0,5 & 0 & 2,8 & 0,5 & 1,2 & 0,4 & 7,6 & 0,131578947 \\
\hline şÜ & 4 & 4 & 3,7 & 0 & 3,8 & 4 & 4 & 23,5 & 0,042553191 \\
\hline MK & 3,8 & 4 & 1,2 & 3,5 & 0 & 1,8 & 0,8 & 15,1 & 0,066225166 \\
\hline MM & 0 & 0,5 & 0,2 & 0 & 0 & 0 & 0,2 & 0,9 & 1,111111111 \\
\hline SM & 4 & 3,5 & 3,8 & 4 & 3,5 & 3,5 & 0 & 22,3 & 0,044843049 \\
\hline Toplam & 15,5 & 16,3 & 12,9 & 17,8 & 11,6 & 15,3 & 9,1 & & \\
\hline Bölüm & 0,064516 & 0,06135 & 0,077519 & 0,05618 & 0,086207 & 0,065359 & 0,10989 & & \\
\hline
\end{tabular}


Adım 2: Normalize Edilmiş Direkt Illişki Matrisinin Oluşturulması

Eşitlik 1 ve 2 yardımıyla direkt ilişki matrisi normalleştirilir. (Tablo 5.)

Tablo 5: Normalize Edilmiş Direkt illişki Matrisi

\begin{tabular}{|l|c|c|c|c|c|c|c|}
\hline & FiP & YT & iG & şÜ & MK & MM & SM \\
\hline FiP & 0 & 0,161702 & 0,153191 & 0,170213 & 0,051064 & 0,170213 & 0,106383 \\
\hline YT & 0,06383 & 0 & 0,017021 & 0,148936 & 0,110638 & 0,034043 & 0,051064 \\
\hline iG & 0,093617 & 0,021277 & 0 & 0,119149 & 0,021277 & 0,051064 & 0,017021 \\
\hline şÜ & 0,170213 & 0,170213 & 0,157447 & 0 & 0,161702 & 0,170213 & 0,170213 \\
\hline MK & 0,161702 & 0,170213 & 0,051064 & 0,148936 & 0 & 0,076596 & 0,034043 \\
\hline MM & 0 & 0,021277 & 0,008511 & 0 & 0 & 0 & 0,008511 \\
\hline SM & 0,170213 & 0,148936 & 0,161702 & 0,170213 & 0,148936 & 0,148936 & 0 \\
\hline
\end{tabular}

Adım 3: Toplam ilişki matrisinin (S) elde edilmesi.

S matrisinin hesaplanması için eşitlik 3'de görüldüğü gibi (I-M) matrisine ve bu matrisin tersine ihtiyaç vardır. Bu matrisinin oluşturulması için birim matristen Tablo 6.'daki normalize edilmiş direkt ilişki matrisi çıkarılmış ve bulunan değerler yeni bir matrise aktarılmıştır. Bu matris (I-M) matrisi olup Tablo 6.'da görülmektedir. (I-M) matrisinin tersi alınarak Tablo 7.'de görülen ters matris elde edilir.

Tablo 6: I-M Matrisi

\begin{tabular}{|l|c|c|c|c|c|c|c|}
\hline & FiP & YT & IG & ŞÜ & MK & MM & SM \\
\hline FiP & 1 & $-0,1617$ & $-0,15319$ & $-0,17021$ & $-0,05106$ & $-0,17021$ & $-0,10638$ \\
\hline YT & $-0,06383$ & 1 & $-0,01702$ & $-0,14894$ & $-0,11064$ & $-0,03404$ & $-0,05106$ \\
\hline İ & $-0,09362$ & $-0,02128$ & 1 & $-0,11915$ & $-0,02128$ & $-0,05106$ & $-0,01702$ \\
\hline ŞÜ & $-0,17021$ & $-0,17021$ & $-0,15745$ & 1 & $-0,1617$ & $-0,17021$ & $-0,17021$ \\
\hline MK & $-0,1617$ & $-0,17021$ & $-0,05106$ & $-0,14894$ & 1 & $-0,0766$ & $-0,03404$ \\
\hline MM & 0 & $-0,02128$ & $-0,00851$ & 0 & 0 & 1 & $-0,00851$ \\
\hline SM & $-0,17021$ & $-0,14894$ & $-0,1617$ & $-0,17021$ & $-0,14894$ & $-0,14894$ & 1 \\
\hline
\end{tabular}

Tablo 7: Ters Matris

\begin{tabular}{|l|c|c|c|c|c|c|c|}
\hline & FiP & YT & IG & ŞÜ & MK & MM & SM \\
\hline FiP & 1,174371 & 0,326714 & 0,287539 & 0,347782 & 0,190493 & 0,331509 & 0,215014 \\
\hline YT & 0,184799 & 1,135519 & 0,122999 & 0,267874 & 0,200886 & 0,157259 & 0,13351 \\
\hline IG & 0,170904 & 0,11519 & 1,078777 & 0,201847 & 0,08913 & 0,141349 & 0,08102 \\
\hline ŞÜ & 0,36982 & 0,385731 & 0,327544 & 1,256127 & 0,315188 & 0,374296 & 0,292339 \\
\hline MK & 0,29819 & 0,323908 & 0,183549 & 0,313454 & 1,127265 & 0,232462 & 0,145094 \\
\hline MM & 0,008481 & 0,028217 & 0,014581 & 0,010769 & 0,007581 & 1,007537 & 0,013257 \\
\hline SM & 0,363674 & 0,361458 & 0,326963 & 0,393829 & 0,299425 & 0,351096 & 1,142928 \\
\hline
\end{tabular}


S matrisinin hesaplanması için eşitlik 3'de görüldüğü gibi Tablo 5'deki normalize edilmiş direkt ilişki matrisi ile Tablo 7.'deki ters matrisin çarpılması gerekmektedir. Bu iki matrisin çarpımı sonucu Tablo 8'deki S Matrisi (Toplam ilişki matrisi) bulunmuştur.

Tablo 8: S Matrisi

\begin{tabular}{|l|c|c|c|c|c|c|c|}
\hline & FiP & YT & IG & ŞÜ & MK & MM & SM \\
\hline FİP & 0,174371 & 0,326714 & 0,287539 & 0,347782 & 0,190493 & 0,331509 & 0,215014 \\
\hline YT & 0,184799 & 0,135519 & 0,122999 & 0,267874 & 0,200886 & 0,157259 & 0,13351 \\
\hline IG & 0,170904 & 0,11519 & 0,078777 & 0,201847 & 0,08913 & 0,141349 & 0,08102 \\
\hline ŞÜ & 0,36982 & 0,385731 & 0,327544 & 0,256127 & 0,315188 & 0,374296 & 0,292339 \\
\hline MK & 0,29819 & 0,323908 & 0,183549 & 0,313454 & 0,127265 & 0,232462 & 0,145094 \\
\hline MM & 0,008481 & 0,028217 & 0,014581 & 0,010769 & 0,007581 & 0,007537 & 0,013257 \\
\hline SM & 0,363674 & 0,361458 & 0,326963 & 0,393829 & 0,299425 & 0,351096 & 0,142928 \\
\hline
\end{tabular}

Adım 4: Gönderici ve alıcı grubu hesaplanması.

Eşitlik 5 ve 6 yardımıyla gönderici ve alıcı grubu hesaplanır. Tablo 8'de görülen matriste her bir satır ve sütunun toplamları ayrı ayrı alınıp $D$ ve $R$ değerleri bulunmuştur. Bu sonuçlara göre $D+R$ ve D-R'ler hesaplanmıştır. Tablo 9'da D-R'de pozitif değerlere sahip olan FiP, ŞÜ, MK ve SM kriterleri diğer kriterler üzerinde daha yüksek etkiye sahip olmakla birlikte daha yüksek önceliktedirler. Bu kriterler gönderici yada etkileyici konumundadırlar. D-R'de negatif değerlere sahip olan YT, IG ve MM diğer kriterlere göre daha fazla etkilenirler. Bu kriterler daha düşük önceliğe sahip olduklarından alıcı olarak adlandırılırlar. $\mathrm{D}+\mathrm{R}$ değerleri her bir kriterin diğer kriterlerle olan ilişkisini göstermektedir. D+R'de değeri yüksek olan FiP, şü ve SM kriterleri diğer kriterlerle daha çok ilişkilidir. YT, IG, MK ve MM diğer kriterlere nazaran daha az ilişkiye sahip kriterlerdir. Etki yönlü graf diyagramı (the impact-digraph-map of total relation) Şekil 2.'de görülmektedir.
Tablo 9: D+R VE D-R Değerleri

\begin{tabular}{|l|c|c|}
\hline & $\mathrm{D}+\mathrm{R}$ & $\mathrm{D}-\mathrm{R}$ \\
\hline FiP & 3,443661254 & 0,303181 \\
\hline YT & 2,879581079 & $-0,47389$ \\
\hline İG & 2,220167861 & $-0,46373$ \\
\hline ŞÜ & 4,112726633 & 0,529363 \\
\hline MK & 2,853888766 & 0,393954 \\
\hline MM & 1,685930255 & $-1,50508$ \\
\hline SM & 3,262532633 & 1,216212 \\
\hline
\end{tabular}

Şekil 2: Etki Yönlü Graf Diyagramı

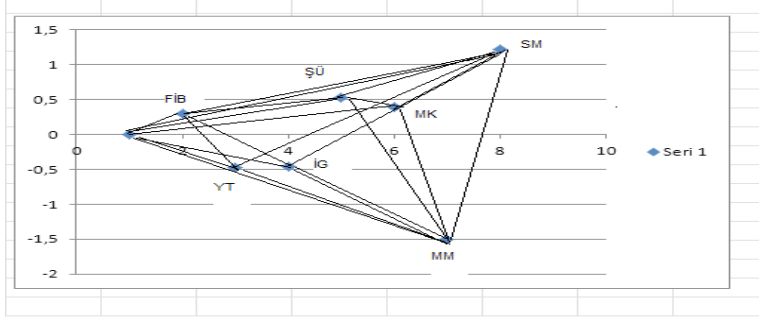

Adım 5: Ağırlıkların Hesaplanması

Eşitlik 7 ve 8 yardımıyla Tablo 10.'da görülen kriter ağırlıklar hesaplanır.

Tablo 10: Kriter Ağırlıkları

\begin{tabular}{|l|c|c|c|c|c|c|c|}
\hline & FiP & YT & IG & ŞÜ & MK & MM & SM \\
\hline $\begin{array}{l}\text { Kriter } \\
\text { Ağırlıkları }\end{array}$ & 0,1676 & 0,1279 & 0,0910 & 0,1960 & 0,1366 & 0,1210 & 0,1599 \\
\hline
\end{tabular}




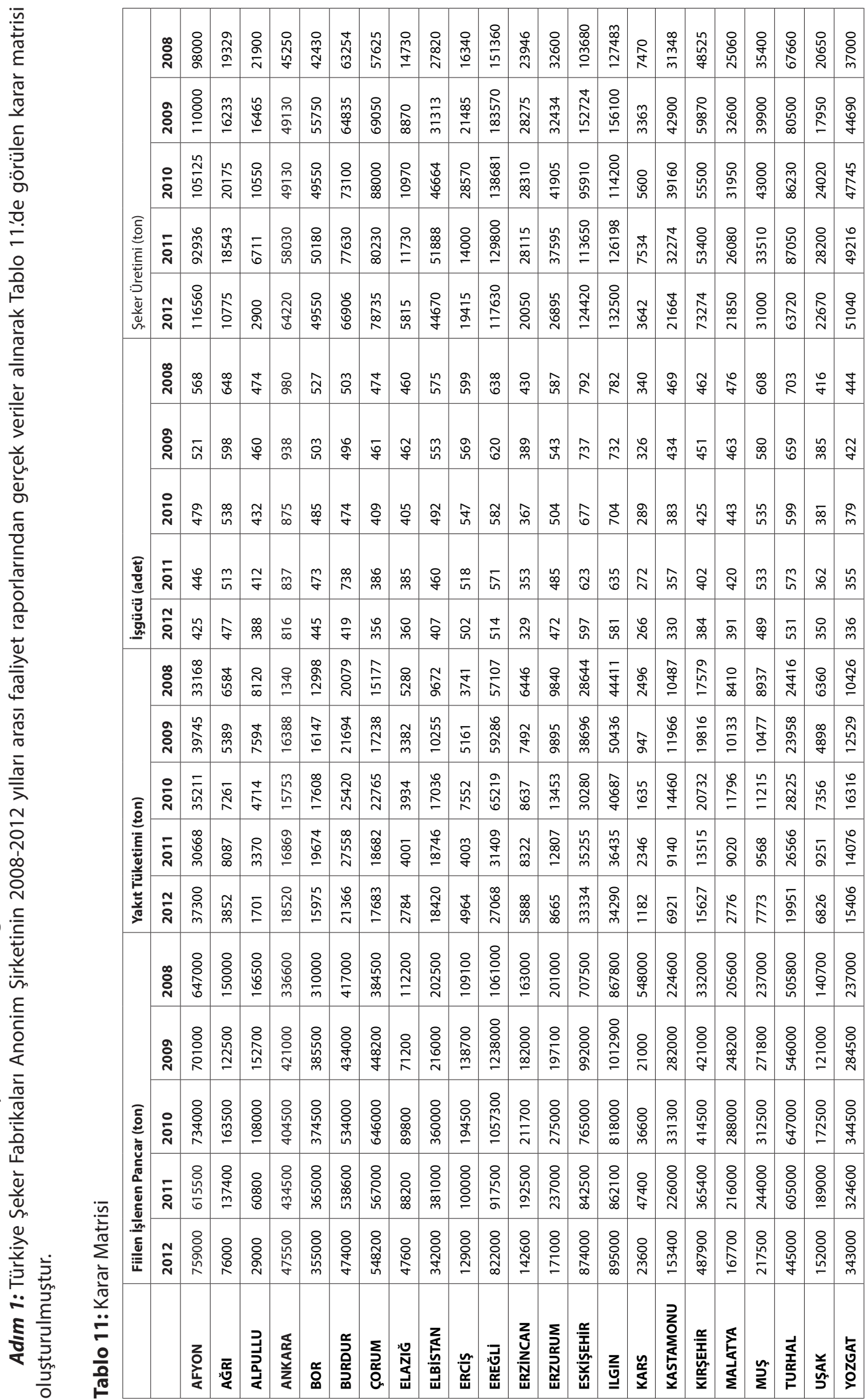




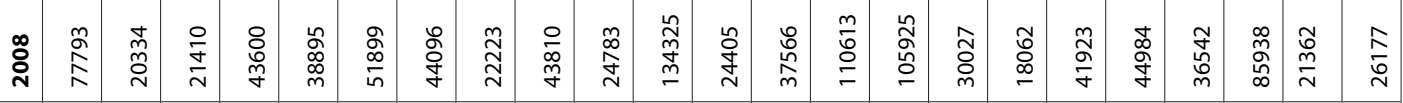

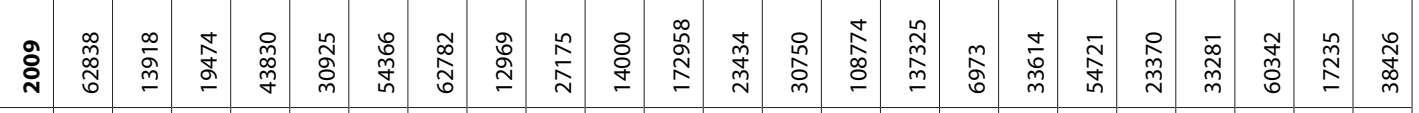

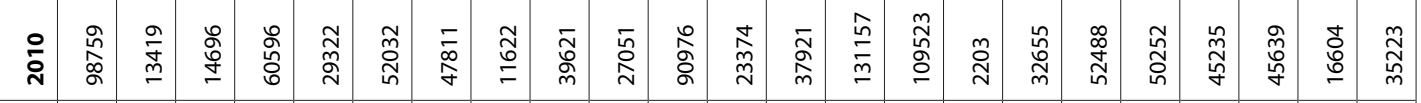

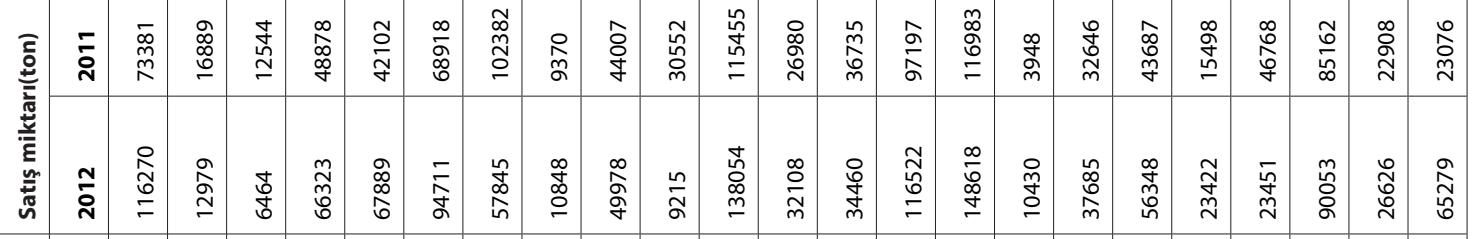

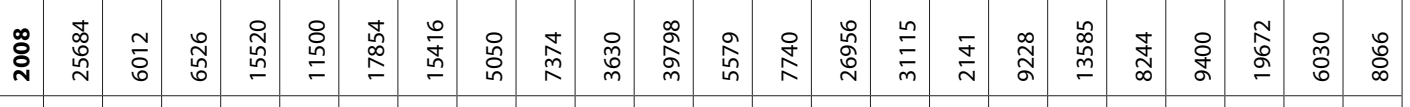

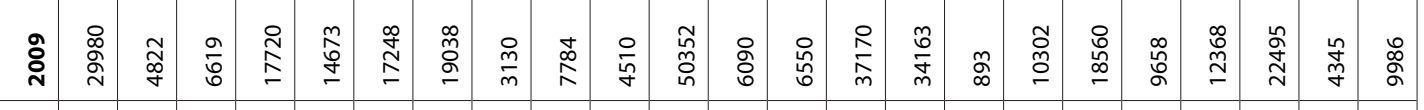

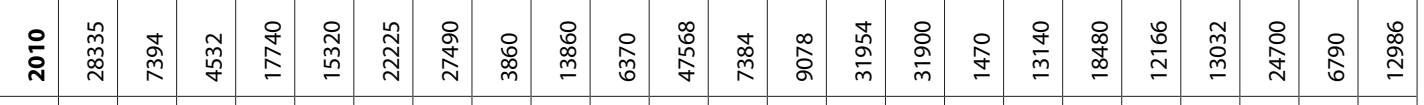

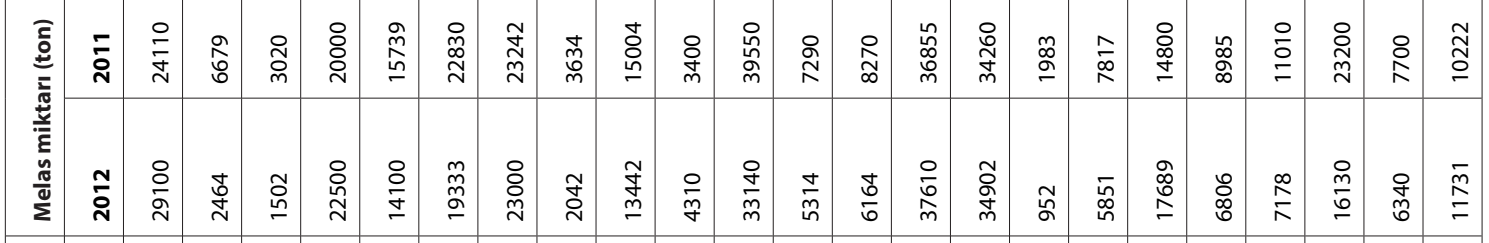

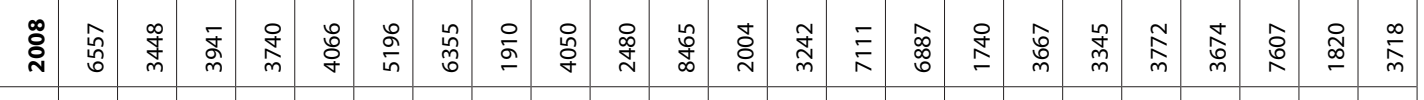

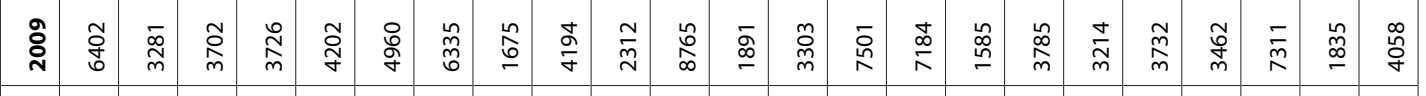

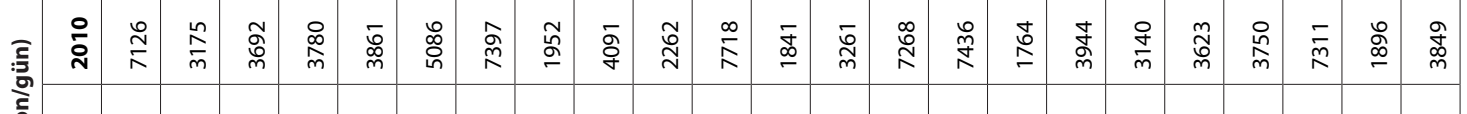

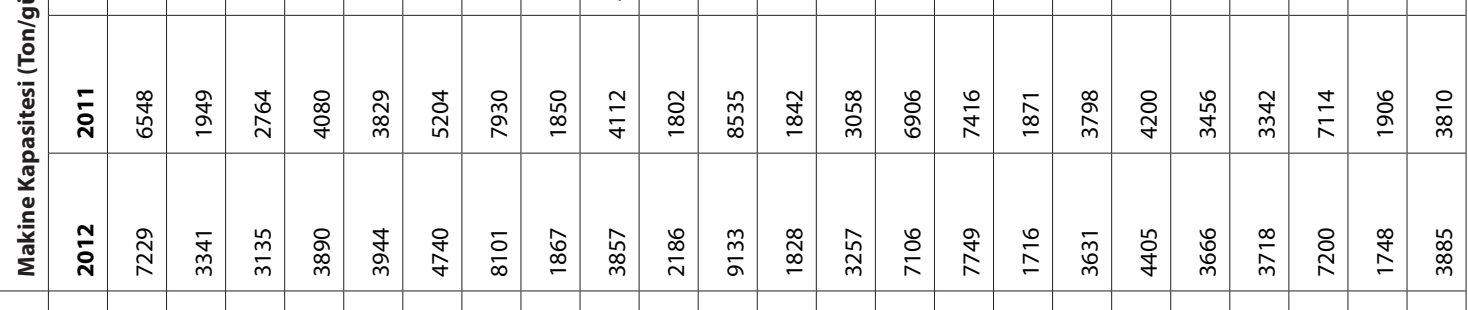

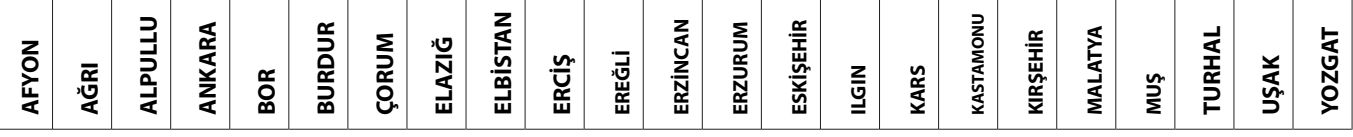




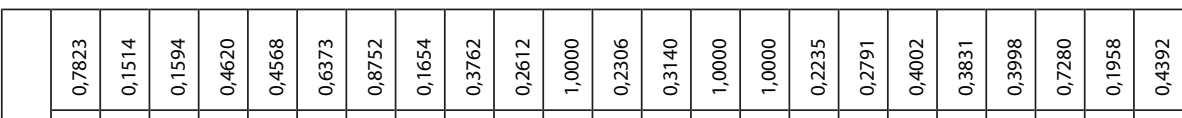

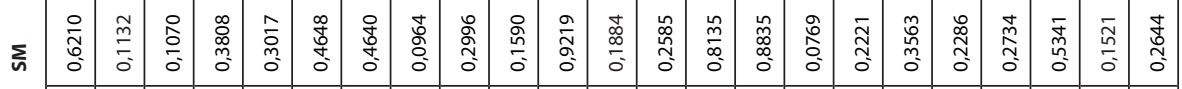

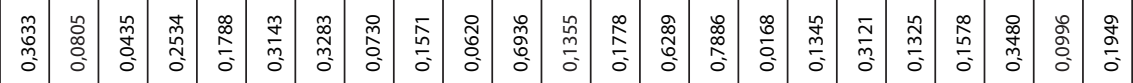

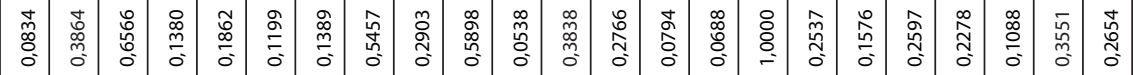

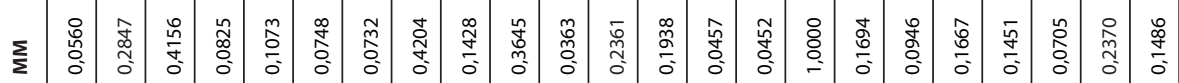

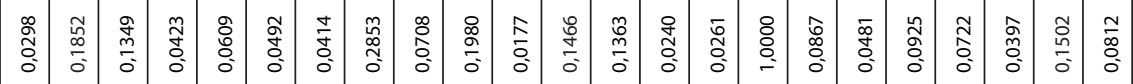

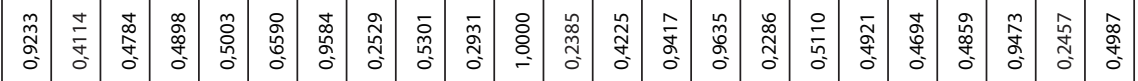

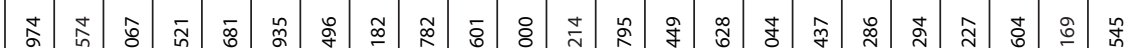

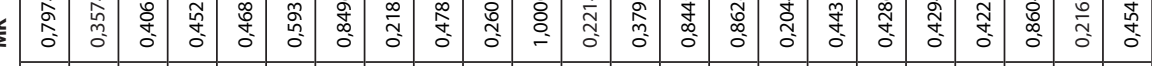

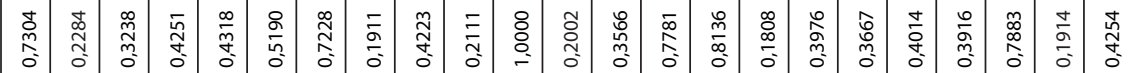

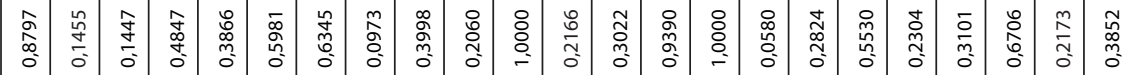

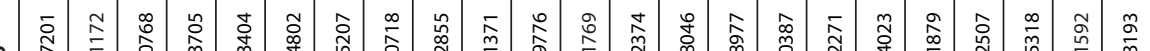

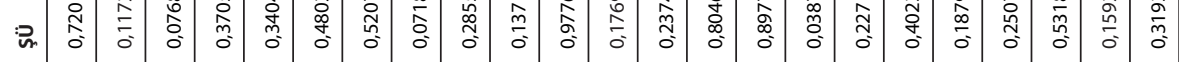

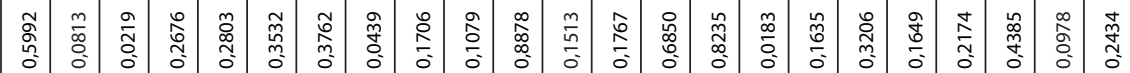

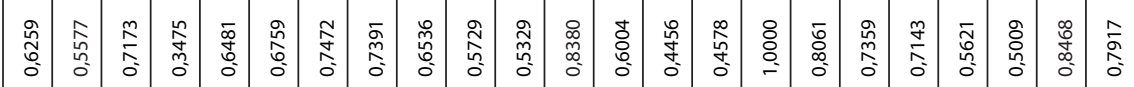

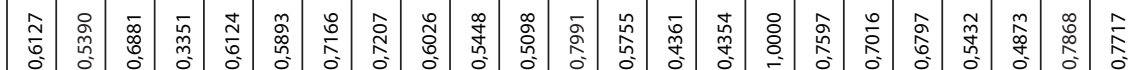

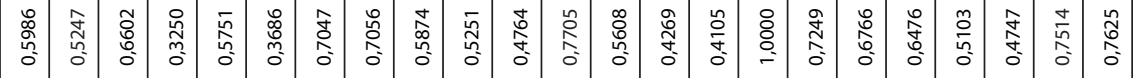

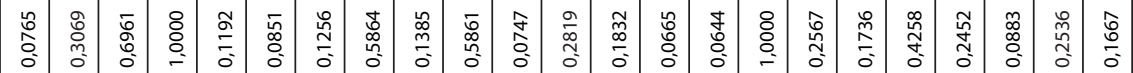

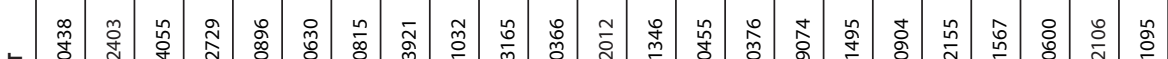
5 5

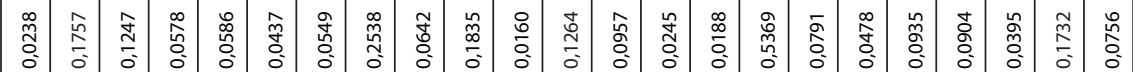

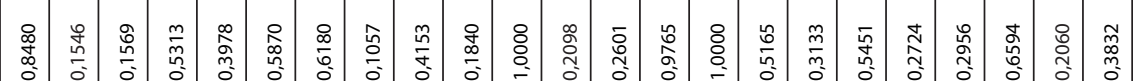
党

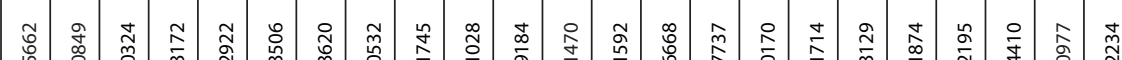

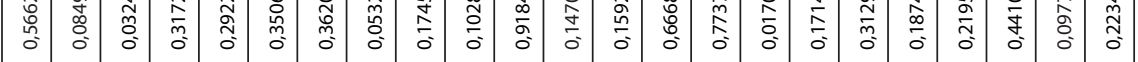

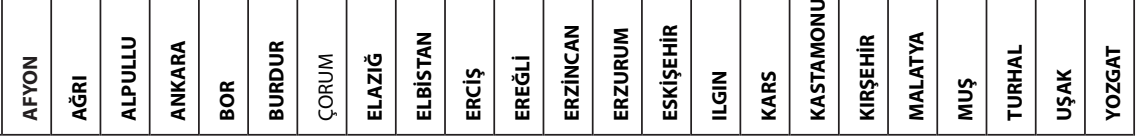


Adım 4: Pozitif $\left(A^{+}\right)$ve negatif ideal çözüm $\left(A^{-}\right)$değerleri 14 ve 15 numaralı eşitlik yardımıyla bulunmuş ve bu değerler Tablo 13.'de görülmektedir.

Tablo 13: Pozitif İdeal $\left(A^{+}\right)$ve Negatif İdeal Çözüm $\left(A^{-}\right)$Değerleri

\begin{tabular}{|l|l|r|}
\hline & \multicolumn{1}{|c|}{$\mathbf{A}^{-}$} & $(0.1483,0.1588,0.1614)$ \\
\hline FiP & $(0.0027,0.0128,0.0171)$ & $(0.0022,0.0050,0.0088)$ \\
\hline YT & $(0.0732,0.1237,0.1363)$ & $(0.0344,0.0355,0.0368)$ \\
\hline IG & $(0.1059,0.1059,0.1059)$ & $(0.1719,0.1893,0.1937)$ \\
\hline ŞÜ & $(0.0035,0.0075,0.0112)$ & $(0.1345,0.1345,0.1345)$ \\
\hline MK & $(0.0243,0.0275,0.0308)$ & $(0.0019,0.038,0.057)$ \\
\hline SM & $(0.1055,0.1055,0.1055)$ & $(0.1282,0.1499,0.1626)$ \\
\hline
\end{tabular}

Adım 5: Eşitlik 16 ve 17 yardımıyla hesaplanan kriter bazında alternatiflerden negatif ideal çözüme uzaklıklar $\left(d_{i j}\right)$ ve pozitif ideal çözüme uzaklıklar Tablo 14. ve Tablo 15.'de görülmektedir.

Tablo 14: Kriter Bazında Alternatiflerden Negatif İdeal Çözüme Uzaklıklar $\left(d_{i j}\right)$

\begin{tabular}{|l|c|c|c|c|c|c|c|}
\hline & FiP & YT & IG & ŞÜ & MK & MM & SM \\
\hline AFYON & 0,6353 & 0,7878 & 0,3878 & 0,7016 & 0,6154 & 0,7597 & 0,4856 \\
\hline AĞRI & 0,0553 & 0,5933 & 0,4598 & 0,0770 & 0,1404 & 0,5441 & 0,0618 \\
\hline ALPULLU & 0,0323 & 0,4139 & 0,3123 & 0,0547 & 0,2031 & 0,3914 & 0,0762 \\
\hline ANKARA & 0,3558 & 0,4590 & 0,6642 & 0,3436 & 0,2512 & 0,7268 & 0,2549 \\
\hline BOR & 0,2796 & 0,7468 & 0,3893 & 0,2987 & 0,2623 & 0,6974 & 0,2509 \\
\hline BURDUR & 0,4074 & 0,7731 & 0,4734 & 0,4467 & 0,3877 & 0,7372 & 0,3708 \\
\hline ÇORUM & 0,4357 & 0,7481 & 0,2778 & 0,4805 & 0,6436 & 0,7304 & 0,4897 \\
\hline ELAZIĞ & 0,0209 & 0,4150 & 0,2785 & 0,0331 & 0,0172 & 0,4252 & 0,1308 \\
\hline ELBiSTAN & 0,2377 & 0,7331 & 0,3865 & 0,2588 & 0,2734 & 0,6425 & 0,1860 \\
\hline ERCiŞ & 0,0732 & 0,4638 & 0,4528 & 0,1149 & 0,0522 & 0,4367 & 0,1080 \\
\hline EREĞLi & 0,9000 & 0,7928 & 0,4942 & 0,9174 & 0,7956 & 0,7798 & 0,6940 \\
\hline ERZiNCAN & 0,1106 & 0,6279 & 0,1994 & 0,1437 & 0,0159 & 0,5666 & 0,0887 \\
\hline ERZURUM & 0,1432 & 0,6974 & 0,4214 & 0,2034 & 0,1818 & 0,6254 & 0,1407 \\
\hline ESKiŞEHIR & 0,7583 & 0,7909 & 0,5639 & 0,7761 & 0,6521 & 0,7655 & 0,6492 \\
\hline ILGIN & 0,8159 & 0,7959 & 0,5658 & 0,8705 & 0,6767 & 0,7700 & 0,6767 \\
\hline KARS & 0,2389 & 0,0000 & 0,0000 & 0,0000 & 0,0000 & 0,0000 & 0,2559 \\
\hline KASTAMONU & 0,1740 & 0,6674 & 0,2387 & 0,1887 & 0,2477 & 0,6447 & 0,1162 \\
\hline KIRŞEHIR & 0,3568 & 0,7279 & 0,2963 & 0,3952 & 0,2268 & 0,7140 & 0,2165 \\
\hline MALATYA & 0,1591 & 0,5788 & 0,3206 & 0,1565 & 0,2290 & 0,6435 & 0,1903 \\
\hline MUŞ & 0,1879 & 0,6665 & 0,4620 & 0,2222 & 0,2297 & 0,6651 & 0,1877 \\
\hline TURHAL & 0,4816 & 0,7739 & 0,5125 & 0,5148 & 0,6623 & 0,7434 & 0,4261 \\
\hline UŞAK & 0,0858 & 0,6258 & 0,2088 & 0,1241 & 0,0137 & 0,5768 & 0,0696 \\
\hline YOZGAT & 0,2378 & 0,7173 & 0,2250 & 0,2807 & 0,2552 & 0,6492 & 0,2434 \\
\hline
\end{tabular}


Tablo 15: Kriter Bazında Alternatiflerden Pozitif İdeal Çözüme Uzaklıklar $\left(d_{i}\right)$

\begin{tabular}{|l|c|c|c|c|c|c|c|}
\hline & FiP & YT & IG & ŞÜ & MK & MM & SM \\
\hline AFYON & 0,2832 & 0,0093 & 0,2765 & 0,2338 & 0,1997 & 0,0205 & 0,2840 \\
\hline AĞRI & 0,8456 & 0,2048 & 0,2046 & 0,8408 & 0,6720 & 0,2397 & 0,7042 \\
\hline ALPULLU & 0,8724 & 0,4270 & 0,3529 & 0,8742 & 0,6004 & 0,4112 & 0,6991 \\
\hline ANKARA & 0,5512 & 0,5577 & 0,0000 & 0,5827 & 0,5450 & 0,0554 & 0,4868 \\
\hline BOR & 0,6207 & 0,0505 & 0,2767 & 0,6195 & 0,5340 & 0,0867 & 0,4934 \\
\hline BURDUR & 0,5013 & 0,0251 & 0,2411 & 0,4812 & 0,4135 & 0,0442 & 0,3728 \\
\hline ÇORUM & 0,4750 & 0,0493 & 0,3870 & 0,4487 & 0,1837 & 0,0536 & 0,3029 \\
\hline ELAZIĞ & 0,8880 & 0,3896 & 0,3860 & 0,8846 & 0,7797 & 0,3603 & 0,6887 \\
\hline ELBiSTAN & 0,6738 & 0,0639 & 0,2793 & 0,6717 & 0,5250 & 0,1498 & 0,5533 \\
\hline ERCiŞ & 0,8285 & 0,3552 & 0,2120 & 0,8052 & 0,7460 & 0,3629 & 0,6388 \\
\hline EREĞLi & 0,0000 & 0,0059 & 0,1711 & 0,0000 & 0,0000 & 0,0000 & 0,1922 \\
\hline ERZiNCAN & 0,7906 & 0,1699 & 0,4670 & 0,7740 & 0,7801 & 0,2227 & 0,6493 \\
\hline ERZURUM & 0,7572 & 0,1001 & 0,2431 & 0,7166 & 0,6144 & 0,1576 & 0,6061 \\
\hline ESKiŞEHIR & 0,1747 & 0,0072 & 0,1003 & 0,1578 & 0,1599 & 0,0158 & 0,2374 \\
\hline ILGIN & 0,1063 & 0,0017 & 0,0992 & 0,0592 & 0,1353 & 0,0101 & 0,2212 \\
\hline KARS & 0,7695 & 0,7969 & 0,6642 & 0,9174 & 0,7956 & 0,7798 & 0,6625 \\
\hline KASTAMONU & 0,7283 & 0,1338 & 0,4284 & 0,7309 & 0,5512 & 0,1387 & 0,6205 \\
\hline KIRŞEHIR & 0,5529 & 0,0727 & 0,3691 & 0,5331 & 0,5732 & 0,0688 & 0,5321 \\
\hline MALATYA & 0,7417 & 0,2371 & 0,3451 & 0,7612 & 0,5673 & 0,1407 & 0,5562 \\
\hline MUŞ & 0,7127 & 0,1325 & 0,2030 & 0,6961 & 0,5680 & 0,1185 & 0,5517 \\
\hline TURHAL & 0,4255 & 0,0236 & 0,1518 & 0,4119 & 0,1495 & 0,0374 & 0,3507 \\
\hline UŞAK & 0,8150 & 0,1740 & 0,4601 & 0,7972 & 0,7823 & 0,2090 & 0,6745 \\
\hline YOZGAT & 0,6650 & 0,0803 & 0,4394 & 0,6394 & 0,5413 & 0,1383 & 0,5112 \\
\hline
\end{tabular}

Adım 6: $A_{i}$ alternatifinden pozitif ideal çözüme $\left(A^{+}\right)$ve negatif ideal çözüme $\left(A^{-}\right)$olan uzaklıklar eşitlik 18 ve eşitlik 19 yardımıyla ağırlıklandırıır. Ağırlıklandırılmış uzaklık değerleri $\left(D^{-}\right)$ve $\left(D^{+}\right)$Tablo 16.'da görülmektedir.

Tablo 16: Negatif ve Pozitif İdeal Çözüme Göre Ağırlıklandırılmış Uzaklık Değerleri

\begin{tabular}{|l|c|c|l|c|c|}
\hline Alternatifler & $\left(D_{i}^{-}\right)$ & $\left(D_{i}^{+}\right)$ & Alternatifler & $\left(D_{i}^{-}\right)$ & $\left(D_{i}^{+}\right)$ \\
\hline AFYON & 0,6288 & 0,1968 & ERZURUM & 0,3155 & 0,4983 \\
\hline AĞRI & 0,2397 & 0,5791 & ESKişEHIR & 0,7143 & 0,1322 \\
\hline ALPULLU & 0,1863 & 0,6436 & ILGIN & 0,7511 & 0,0946 \\
\hline ANKARA & 0,4089 & 0,4362 & KARS & 0,0802 & 0,7779 \\
\hline BOR & 0,3957 & 0,4176 & KASTAMONU & 0,3012 & 0,5124 \\
\hline BURDUR & 0,4981 & 0,3240 & KIRŞEHiR & 0,4058 & 0,4124 \\
\hline ÇORUM & 0,5381 & 0,2909 & MALATYA & 0,2985 & 0,5176 \\
\hline ELAZIĞ & 0,1643 & 0,6636 & MUŞ & 0,3448 & 0,4681 \\
\hline ELBiSTAN & 0,3642 & 0,4536 & TURHAL & 0,5741 & 0,2489 \\
\hline ERCiŞ & 0,2159 & 0,6031 & UŞAK & 0,2193 & 0,5954 \\
\hline EREĞLi & 0,7855 & 0,0502 & YOZGAT & 0,3568 & 0,4592 \\
\hline ERZiNCAN & 0,2287 & 0,5842 & & & \\
\hline
\end{tabular}


Adım 7: 20 numaralı eşitlik yardımıyla hesaplanan her bir alternatifin yakınlık katsayıları $\left(D_{i}{ }_{i}\right)$ (Tablo 17'de görülmektedir.

Tablo 17: Alternatiflerin Yakınlık Katsayıları

\begin{tabular}{|l|c|l|c|}
\hline Alternatifler & \multicolumn{1}{|c|}{$A_{i}^{*}$} & Alternatifler & $A_{i}^{*}$ \\
\hline AFYON & 0,761654901 & ERZURUM & 0,387741049 \\
\hline AĞRI & 0,292766107 & ESKişEHIR & 0,843873252 \\
\hline ALPULLU & 0,224527874 & ILGIN & 0,88811905 \\
\hline ANKARA & 0,48384169 & KARS & 0,09343831 \\
\hline BOR & 0,48653512 & KASTAMONU & 0,370161823 \\
\hline BURDUR & 0,605877316 & KIRŞEHIR & 0,495975529 \\
\hline ÇORUM & 0,649088439 & MALATYA & 0,365747574 \\
\hline ELAZIĞ & 0,19847704 & MUŞ & 0,424155386 \\
\hline ELBISTTAN & 0,445333354 & TURHAL & 0,697595029 \\
\hline ERCiŞ & 0,26362784 & UŞAK & 0,269206129 \\
\hline EREĞLi & 0,939949569 & YOZGAT & 0,437245718 \\
\hline ERZINCAN & 0,281375675 & & \\
\hline
\end{tabular}

Adım 8: Yakınlık katsayılarının azalan şekilde sıralanması Tablo 18.'de görülmektedir.

Tablo 18: Alternatiflerin Yakınlık Katsayılarının Sıralanması

\begin{tabular}{|l|l|l|l|l|l|l|l|l|}
\hline Sıra & Alternatifler & $A_{i}^{*}$ & Sıra & Alternatifler & $A_{i}^{*}$ & Sıra & Alternatifler & $A_{i}^{*}$ \\
\hline 1 & EREĞLi & 0,9399 & 9 & BOR & 0,4865 & 17 & AĞRI & 0,2928 \\
\hline 2 & ILGIN & 0,8881 & 10 & ANKARA & 0,4838 & 18 & ERZiNCAN & 0,2814 \\
\hline 3 & ESKIŞEHIR & 0,8439 & 11 & ELBiSTAN & 0,4453 & 19 & UŞAK & 0,2692 \\
\hline 4 & AFYON & 0,7617 & 12 & YOZGAT & 0,4372 & 20 & ERCiş & 0,2636 \\
\hline 5 & TURHAL & 0,6976 & 13 & MUŞ & 0,4242 & 21 & ALPULLU & 0,2245 \\
\hline 6 & ÇORUM & 0,6491 & 14 & ERZURUM & 0,3877 & 22 & ELAZIĞ & 0,1985 \\
\hline 7 & BURDUR & 0,6059 & 15 & KASTAMONU & 0,3702 & 23 & KARS & 0,0934 \\
\hline 8 & KIRŞEHIR & 0,4960 & 16 & MALATYA & 0,3657 & & & \\
\hline
\end{tabular}

\section{SONUÇ}

Bu çalışmada Türkiye Şeker Fabrikaları A.Ş bünyesindefaaliyetgösteren23fabrikanın performans değerlendirmesi yapıımıştır. Çalışmada son iki yıldır faaliyet göstermeyen Çarşamba ve Susurlukfabrikaları çalışmanın sonucunu olumsuz etkileyeceğinden değerlendirmeye alınmamıştır. Çalışmada uzman görüşlerine başvurularak fiilen işlenen pancar, yakıt tüketimi, iş gücü, şeker üretimi, makine kapasitesi, melas miktarı ve satış miktarı kriter olarak seçilmiştir. Çalışmada öncelikle DEMATEL yöntemiyle hesaplanan ağırlıklardan yola çıkarak Bulanık TOPSIS yöntemiyle performans değerlendirme yapılmıştır.
Bulanık TOPSIS yöntemi uygulanırken 2008-2012 yılları arasında gerçekleşen verilere öncelikle normalizasyon işlemi yapılmıştır. Daha sonra veriler üçgen bulanık sayılar yardımıyla bulanıklaştırılarak bulanık TOPSIS uygulaması gerçekleştirilmiştir. Çalışmanın sonuçları incelendiğinde performans açısından Ereğli, llgın ve Eskişehir ilk üçe giren şeker fabrikaları olmuştur. Performans sıralamasında en düşük değerleri ise Alpullu, Elazığ ve Kars işletmeleridir. Çalışmada kullanılan alternatifler ve kriterler doğrultusunda diğer çok kriterli karar verme yöntemleri ile performans değerlemesi yapılabileceği gibi farklı alanlarda da yeni çalışmalar yapılabilir. 


\section{KAYNAKLAR}

AKSAKAL, E. ve DAĞDEVIREN, M. (2010) "ANP ve DEMATEL Yöntemleri İle Personel Seçimi Problemine Bütünleşik Bir Yaklaşım", Gazi üniversitesi, Mühendislik Mimarlık Fakültesi Dergisi, 25(4): 905-913.

AMIRI, M.P. (2010) "Project Selection For Oil-Fields Development By Using The AHP And Fuzzy TOPSIS Methods", Expert Systems with Applications, 37(9): 6218-6224.

ASLAN, Ş. (2007) "Performans Ölçümünde Kıyaslama Yöntemi Olarak Veri Zarflama Analizinin Kullanımı: Türkiye Şeker Fabrikaları Örneği", Atatürk Üniversitesi, Iktisadi ve Idari Bilimler Dergisi, 21(1): 383-396.

AWASTHI, A. ve CHAUHAN, S.S. (2012) "A Hybrit Approach Integrating Affinity Diagram, AHP And Fuzzy TOPSIS For Sustainable City Logistics Planning", Applied Mathematical Modelling, 36(2): 573-584.

BAI, C. ve SARKIS, J. (2013) "A Grey-Based DEMATEL Model For Evaluating Business Process Management Critical Success Factors", International Journal of Production Economics, 146(1): 281-292.

BAŞKAYA, Z. ve ÖZTÜRK, B. (2011) “Bulanık TOPSIS İle Satış Elemanı Adaylarının Değerlemesi", İşletme ve Ekonomi Araştırmaları Dergisi, 2(2): 77-100.

BAYKAL, N. ve BEYAN, T. (2004) Bulanık Mantık Illke ve Temelleri, Bıçaklar Kitabevi, Ankara.

BAYKASOĞLU, A., KAPLANOĞLU, V., DURMUŞOĞLU, Z.D.U. ve ŞAHİN, C. (2013)“Integrating Fuzzy DEMATEL And Fuzzy Hierarchical TOPSIS Methods For Truck Selection", Expert Systems with Applications, 40(3): 899-907.

BENITEZ, J.M., MARTIN, J.C. ve ROMAN, C. (2007) "Using Fuzzy Number For Measuring Quality Of Service in The Hotel Industry", Tourism Management, 28(2): 544-555.

BORAN, F.E., GENÇ, S., KURT, M. ve AKAY, D. (2009) "A Multi-Criteria Intuitionistic Fuzzy Group Decision Making For Supplier Selection With TOPSIS Method", Expert Systems with Applications, 36(8): 11363-11368.

CHEN, C.T., LIN, C.T. ve HUANG, S.F. (2006) "A Fuzzy Approach For Supplier Evaluation And Selection in Supply Chain Management", International Journal of Production Economics, 102(2): 289-301.
CHEN, C.T. (2000) "Extensions of the TOPSIS for Group Decision-Making Under Fuzzy Environment", Fuzzy Sets and Systems, 114(1): 1-9.

ÇAKIR, S. ve PERÇIN, S. (2012) "Kamu Şeker Fabrikalarında Etkinlik Ölçümü: VZA-Malmquist TFV Uygulaması", Anadolu Üniversitesi Sosyal Bilimler Dergisi, 12(4): 49-63.

ÇINAR TIRMIKÇIOĞLU, N. (2010) “Kuruluş Yeri Seçiminde Bulanık TOPSIS Yöntemi Ve Bankacılık Sektöründe Bir Uygulama", Karamanoğlu Mehmetbey Üniversitesi,Sosyal ve Ekonomik Araştırmalar Dergisi, 18(12): 37-45.

DAĞDEVIREN, M., YAVUZ, S. ve KILINC, N. (2009) "Weapon Selection Using The AHP And TOPSIS Methods Under Fuzzy Environment", Expert Systems with Applications, 36(4): 8143-8151.

DALALAH, D., HAYAJNEH, M. ve BATIEHA, F. (2011)

"A Fuzzy Multi-Criteria Decision Making Model For Supplier Selection", Expert Systems with Applications, 38(7): 8384-8391.

DEMIR, H.H. (2010) İmalat Sektöründe Bulanık TOPSIS Yöntemiyle Tedarikçi Seçimi, Yayınlanmış Yüksek Lisans Tezi, İstanbul Üniversitesi, Sosyal Bilimler Enstitüsü, İstanbul.

ECER, F. (2006) "Bulanık Ortamlarda Grup Kararı Vermeye Yardımcı Bir Yöntem: Fuzzy TOPSIS ve Bir Uygulama", Dokuz Eylül Üniversitesi, Işletme Fakültesi Dergisi, 7(2): 77-96.

ELEREN, A. ve ERSOY, M. (2007) "Mermer Blok Kesim Yöntemlerinin Bulanık TOPSIS Yöntemiyle Değerlendirilmesi", TMMOB Madencilik Dergisi, 46(3): 9-22.

FONTELA, E. ve GABUS, A. (1974) “Dematel, Innovative Metods", Report No 2 Structural Analysis Of The World Problematique, Battelle Geneva Research Institute, 67-69.

HUANG, J.H. ve PENG, K.H. (2012) “Fuzzy Rasch Model in TOPSIS: A New Approach For Generating Fuzzy Numbers To Assess The Competitiveness Of The Tourism Industries in Asian Countries", Tourism Management, 33(2): 456-465.

KABAK, M. (2011) “Birlik Hava Savunma Önceliklerinin Tespitine Bulanık Bir Yaklaşım”, Savunma Bilimleri Dergisi, 10(2): 1-17. 
KANNAN, G., POKHAREL, S. ve KUMAR, P.S. (2009) “A Hybrid Approach Using ISM And Fuzzy TOPSIS For The Selection Of Reverse Logistics Provider", Resources, Conservation and Recycling, 54(1): 28-36.

KAYA, I., KILINÇ. M.S. ve ÇEVIKCAN, E. (2007) "MakineTechizat Seçim Probleminde Bulanık Karar Verme Süreci", Mühendis ve Makine, 49(576): 8-14.

KIYMAZ, T. (2001) “Dünyada Şeker Politikaları ve Yeni Şeker Kanunu Sonrası Türkiye'nin Seçenekleri", Gıda Mühendisliği Dergisi, 11: 8-10

MADI, E.N. ve OSMAN, A. (2011) "Fuzzy TOPSIS Method in The Selection Of Investment Boards By Incorporating Operational Risks", Proceedings Of The World Congress On Engineering 2011, WCE 2011, 6-8 July 2011, London, U.K.

MULLINER, E., SMALLBONE, K. ve MALIENE, V. (2013) "An Assessment of Sustainable Housing Affordability Using a Multiple Criteria Decision Making Method", Omega, 41(2): 270-279.

PERÇIN, S. ve KARAKAYA, A. (2012) "Bulanık Karar Verme Yöntemleriyle Türkiye'de Bilişim

Teknolojisi Firmalarının Finansal Performanslarının Değerlendirilmesi", Marmara Üniversitesi i.I.l.B.F Dergisi, XXXIII(II): 241-266.

SEYED-HOSSEINI, S.M., SAFAEI, N. ve ASGHARPOUR, M.J., (2006) "Reprioritization of Failures in A System Failure Mode And Effects Analysis By Decision Making Trial And Evaluation Laboratory Technique", Reliability Engineering and System Safety, 91(8): 872-881.

SHIH, H.S., SHYUR, H.J. ve LEE, E.S. (2007) “An Extension of TOPSIS for Group Decision Making", Mathematical and Computer Modelling, 45: 801-813.

TAŞDOĞAN, B. ve TAŞDOĞAN, C. (2012) "Türkiye Şeker Fabrikaları A.Ş'nin Malmquist Endeksi Çerçevesinde Etkinlik Analizi", Akdeniz i.I.B.F Dergisi, 12(23): 59-77.
TSAI, W.H. ve CHOU, W.C. (2009) "Selecting Management Systems For Sustainable Development in SMEs: A Novel Hybrid Model Based On DEMATEL, ANP, and ZOGP", Expert Systems with Applications, 36(2): 1444-1458.

Türkiye Şeker Fabrikaları Anonim Şirketi, (2012) Faaliyet Raporu.

WANG, J.W., CHENG, C.H. ve HUANG, K.C. (2009) "Fuzzy Hierarchical TOPSIS For Supplier Selection", Applied Soft Computing, 9(1): 377-386.

WANG, Y.J. ve LEE, H.S. (2010) "Evaluating Financial Performance of Taiwan Container Ship-Ping Companies By Strength And Weakness Indices", International Journal of Computer Mathematics, 78(1): 38-52.

WANG, Y.J. (2008) "Applying FMCDM to Evaluate Financial Performance of Domesticairlines in Taiwan", Expert Systems with Applications, 34(3): 1837-1845.

WANG, Y.J. (2014), "The Evaluation Of Financial Performance For Taiwan Containershipping Companies By Fuzzy TOPSIS", Applied Soft Computing, 22: 28-35.

WU, W.W. ve LEE, Y.T. (2007) "Developing Global Managers' Competencies Using The Fuzzy DEMATEL Method", Expert Systems with Applications, 32(2): 499507.

YANG, J. ve TZENG, G.H. (2011) "An Integrated MCDM Technique Combined with DEMATEL for a Novel Cluster-Weighted with ANP Method", Expert Systems with Applications, 38(3): 1417-1424.

ZEYDAN, M., ÇOLPAN, C. ve ÇOBANOĞLU, C. (2011) "A Combined Methodology For Supplier Selection And Performance Evaluation", Expert Systems with Applications, 38(3): 2741-2751. 